\title{
COMUNICAÇÃO
}

\section{NO CHANGE IN ONE BIOLOGICAL PARAMETER FOR DIPETALOGASTER MAXIMUS AFTER 20 YEARS OF LABORATORY COLONISATION}

\author{
D.J. Meirelles, F.L. Kasten, M.T.A. García-Zapata and P.D. Marsden
}

The value of Dipetalogaster maximus as a xenodiagnostic agent has been reviewed ${ }^{2}$. We have always worried that the due to inbreeding in our laboratory colony our off-spring would suck less blood. An opportunity to test this risk arrived with 60 eggs retrieved from a wild caught female of the Baja California Peninsula. Instars from these eggs were weighed before and after each meal. A control group of same instar bugs from the Brasilia colony which has been in existence twenty years was investigated at the same time. All bugs were maintained at $26^{\circ} \mathrm{C}$ and $70 \%$ humidity and fed on chicken blood. They were weighed individually on a balance sensitive to 0.5 milligram. Thirty individuals of each juvenile instar were used and ten of both sex adults for the two colonies 1973 and 1993. The results are shown in the Tables. The statistical analysis is that of Levine ${ }^{1}$ for comparing samples of different size.

Table 1 shows the summarised data of blood meal weight in the two colonies 1973 and 1993. Table 2 records the $T$ values (actual and expected) and the degree of freedom related to this data. Only two instars were significantly different in the two colonies. The second instar fed significantly more in the 1993 group and adult females the reverse (a stage of more relevance to our colony needs). Possibly if the groups had been larger these differences would also disappear. The data suggest that after twenty years in colony blood ingestion of the different instars of $D$. maximus has not changed.
Table 1-Mean weight in miligrams and standard deviation of blood ingested by instar groups of 1973 and 1993 colonies of Dipetalogaster maximus.

\begin{tabular}{crrrrr}
\hline & \multicolumn{2}{c}{ Colony 1973} & & \multicolumn{2}{c}{ Colony 1993} \\
\cline { 2 - 3 } \cline { 5 - 6 } & mean & SD & & mean & SD \\
\hline 1 & 91 & 15 & & 76 & 32 \\
2 & 174 & 37 & & 255 & 45 \\
3 & 430 & 112 & & 539 & 90 \\
4 & 780 & 322 & & 831 & 217 \\
5 & 988 & 838 & & 618 & 737 \\
0 & 683 & 460 & & 460 & 327 \\
0 & 2203 & 1242 & & 907 & 1006 \\
\hline
\end{tabular}

Table 2 - Statistical significancel of data $(p<0.1)$ comparing the two groups of 1973 and 1993 colonies of Dipetalogaster maximus.

\begin{tabular}{cccc}
\hline Instar & $\begin{array}{c}\text { T value } \\
\text { obtained }\end{array}$ & $\begin{array}{c}\text { T value } \\
\text { expected }\end{array}$ & $\begin{array}{c}\text { Degree of } \\
\text { freedom }\end{array}$ \\
\hline 1 & 1838 & 2704 & 36 \\
2 & 4900 & 2704 & 36 \\
3 & 2495 & 2704 & 36 \\
4 & 394 & 2704 & 36 \\
5 & 1781 & 2704 & 35 \\
0 & 2737 & 3106 & 11 \\
0 & 5470 & 3106 & 11 \\
\hline
\end{tabular}

1 Note: only instar II and females show significance.

\section{ACKNOWLEDGEMENTS}

We wish to thank Prof ${ }^{\mathrm{a}}$. Vanize Macêdo, Coordinator of the Núcleo de Medicina Tropical e Nutrição for laboratory facilities and Dr J.A. Dória for the use of his sensitive balance.

\section{REFERENCES}

Núcleo de Medicina Tropical e Nutrição, Universidade de Brasilia, Brasilia, DF, Brazil and Departamento de Medicina Tropical, Universidad de Guadalajara, Guadalajara, Jalisco, Mexico.

Address to: Dr. Marco Tulio A. García-Zapata. NMTN/UnB. Caixa Postal 04-475, 70919-970 Brasília, DF, Brasil.

Recebido para publicação em 30/06/94.
1. Levine J. Applied Statistics for the Social Sciences. Harper \& Row, New York, 1977. Dipetalogaster maximus as a xenodiagnostic agent. Revista da Sociedade Brasileira de Medicina Tropical 19:205-207, 1986.
2. Marsden PD. Dipetalogaster maxima or 